\title{
The incidence of raised intracranial pressure in nonsyndromic sagittal craniosynostosis following primary surgery
}

\author{
Gregory P. L. Thomas, PhD, FRCS, ${ }^{1}$ David Johnson, DM, FRCS, ${ }^{1}$ Jo C. Byren, MRCGP, 1 \\ Andrew D. Judge, PhD, ${ }^{2,3}$ Jayaratnam Jayamohan, FRCS, ${ }^{1}$ Shailendra A. Magdum, FRCS, ${ }^{1}$ \\ Peter G. Richards, FRCS, ${ }^{1}$ and Steven A. Wall, FCS(SA) Plast ${ }^{1}$
}

${ }^{1}$ Oxford Craniofacial Unit, Oxford University Hospitals NHS Trust, Oxford; ${ }^{2}$ Oxford NIHR Musculoskeletal Biomedical Research Unit, Nuffield Department of Orthopaedics, Rheumatology and Musculoskeletal Sciences, University of Oxford; and ${ }^{3} \mathrm{MRC}$ Lifecourse Epidemiology Unit, University of Southampton, Southampton General Hospital, Southampton, United Kingdom

OBJECT Raised intracranial pressure (ICP) is recognized to occur in patients with nonsyndromic isolated sagittal craniosynostosis (SC) prior to surgery. However, the incidence of raised ICP following primary surgery is rarely reported and there appears to be a widely held assumption that corrective surgery for SC prevents the later development of intracranial hypertension. This study reports the incidence of postoperative raised ICP in a large cohort of patients with SC treated by 1 of 2 surgical procedures in a single craniofacial unit.

METHODS A retrospective review was performed of all patients with SC who underwent either a modified strip craniectomy (MSC) or calvarial remodeling (CR) procedure under the care of the Oxford Craniofacial Unit between 1995 and 2010 and who were followed up for more than 2 years. The influence of patient age at surgery, year of surgery, sex, procedure type, and the presence of raised ICP preoperatively were analyzed.

RESULTS Two hundred seventeen children had primary surgery for SC and were followed up for a mean of 86 months. The overall rate of raised ICP following surgery was $6.9 \%$, occurring at a mean of 51 months after the primary surgical procedure. Raised ICP was significantly more common in those patients treated by MSC (13 of 89 patients, 14.6\%) than CR (2 of 128 patients, $1.6 \%$ ). Also, raised ICP was more common in patients under 1 year of age, the majority of whom were treated by MCS. No other factor was found to have a significant effect.

CONCLUSIONS Postoperative raised ICP was found in more than 1 in 20 children treated for nonsyndromic SC in this series. It was significantly influenced by the primary surgical procedure and age at primary surgery. Careful long-term follow-up is essential if children who develop raised ICP following surgery are not to be overlooked.

http://thejns.org/doi/abs/10.3171/2014.11.PEDS1426

KEY WORDS intracranial pressure; intracranial hypertension; sagittal craniosynostosis; craniofacial

I SOLATED nonsyndromic sagittal craniosynostosis (SC) is the most common type of craniosynostosis, which affects between 1 in 2000 and 1 in 5000 infants worldwide. ${ }^{21,23,51}$ Patients with untreated SC are known to be at risk for developing raised intracranial pressure (ICP), with an estimated incidence of between $4.5 \%$ and $24 \%$ and evidence of increasing frequency with age. $6,13,16,34-36,42,43$ If un- treated, raised ICP can lead to visual loss and psychomotor impairment. . $^{32,49}$

Although outcome studies from surgery for SC abound in the literature, the majority do not report on the incidence or otherwise of raised ICP following surgery. There appears to be a prevalent tacit assumption that a single transcranial procedure is sufficient to treat intracranial hy-

ABBREVIATIONS CR = calvarial remodeling; HR = hazard ratio; ICP = intracranial pressure; $\mathrm{MSC}=$ modified strip craniectomy; $\mathrm{SC}=$ sagittal craniosynostosis. ACCOMPANYING EDITORIAL See pp 347-349. DOI: 10.3171/2014.9.PEDS14350.

SUBMITTED January 18, 2014. ACCEPTED November 10, 2014.

INCLUDE WHEN CITING Published online January 9, 2015; DOI: 10.3171/2014.11.PEDS1426.

DISCLOSURE This work was supported by the Oxford Craniofacial Research Fund. Dr. Judge receives support of non-study-related clinical or research effort from Roche, and serves as a consultant to Antherra. 
pertension and prevent its future development. However, raised ICP is recognized to occur in syndromic craniosynostosis following aesthetically successful corrective surgery and has been reported following variants of vertex strip craniectomy in isolated SC., ${ }^{1,24,32,47}$ Because the clinical symptoms and signs and radiological findings typically associated with intracranial hypertension are not reliable indicators of its presence in craniosynostosis, it is probable that the true incidence of postoperative raised ICP in SC is underestimated. ${ }^{11,45,46} \mathrm{It}$ is also unclear as to whether the rates of postoperative intracranial hypertension reported in the literature are specific to the surgical procedure used or are dependent on other factors.

To answer these questions we performed a retrospective study in a large cohort of patients with long-term follow-up who had been treated for SC. Importantly, patients were regularly reviewed by a multidisciplinary team with a high index of suspicion for intracranial hypertension and a low threshold for performing intraparenchymal ICP monitoring. This approach was followed in an attempt to identify all those who had developed raised ICP.

\section{Methods}

\section{Study Population}

A retrospective review was performed of the medical records of all patients presenting with primary isolated SC to the Oxford Craniofacial Unit between January 1995 and December 2010. Patients were included in this study if they had undergone their primary corrective procedure under the care of the Oxford Craniofacial Unit and had been reviewed for a minimum of 2 years following surgery. Patients were specifically excluded if it was discovered on preoperative imaging or at the time of surgery that they had synostosis of another cranial suture in addition to the sagittal suture or, following review by a clinical geneticist specialist, were identified to have a known genetic mutation associated with craniosynostosis on genetic screening, either prior to surgery or subsequently. Those with SC considered to be secondary to perinatal intraventricular hemorrhage, hydrocephalus, or CSF shunting procedures were also excluded.

\section{Operative Procedures}

Patients underwent 1 of 2 primary procedures during this period. Until 2007, patients who presented at less than 6 months of age underwent a modified sagittal strip craniectomy (MSC). A wide sagittal strip craniectomy was performed, removing a 5- to 8-cm broad strip of the calvaria centered on the sagittal suture extending from the coronal to lambdoid sutures, with or without the addition of lateral barrel staving (Fig. 1).

Patients who were older at presentation underwent a 5-panel total calvarial remodeling (CR) procedure, referred to as the lateral switch rotation technique. In brief, temporoparietal panels are elevated and interlocking osteotomies performed to permit lateral expansion. The panels are then either rotated through $180^{\circ}$ in situ or switched from side to side to correct for temporal pinching. The frontal and occipital panels are raised and a crescentshaped strip is excised from their inferior margins to
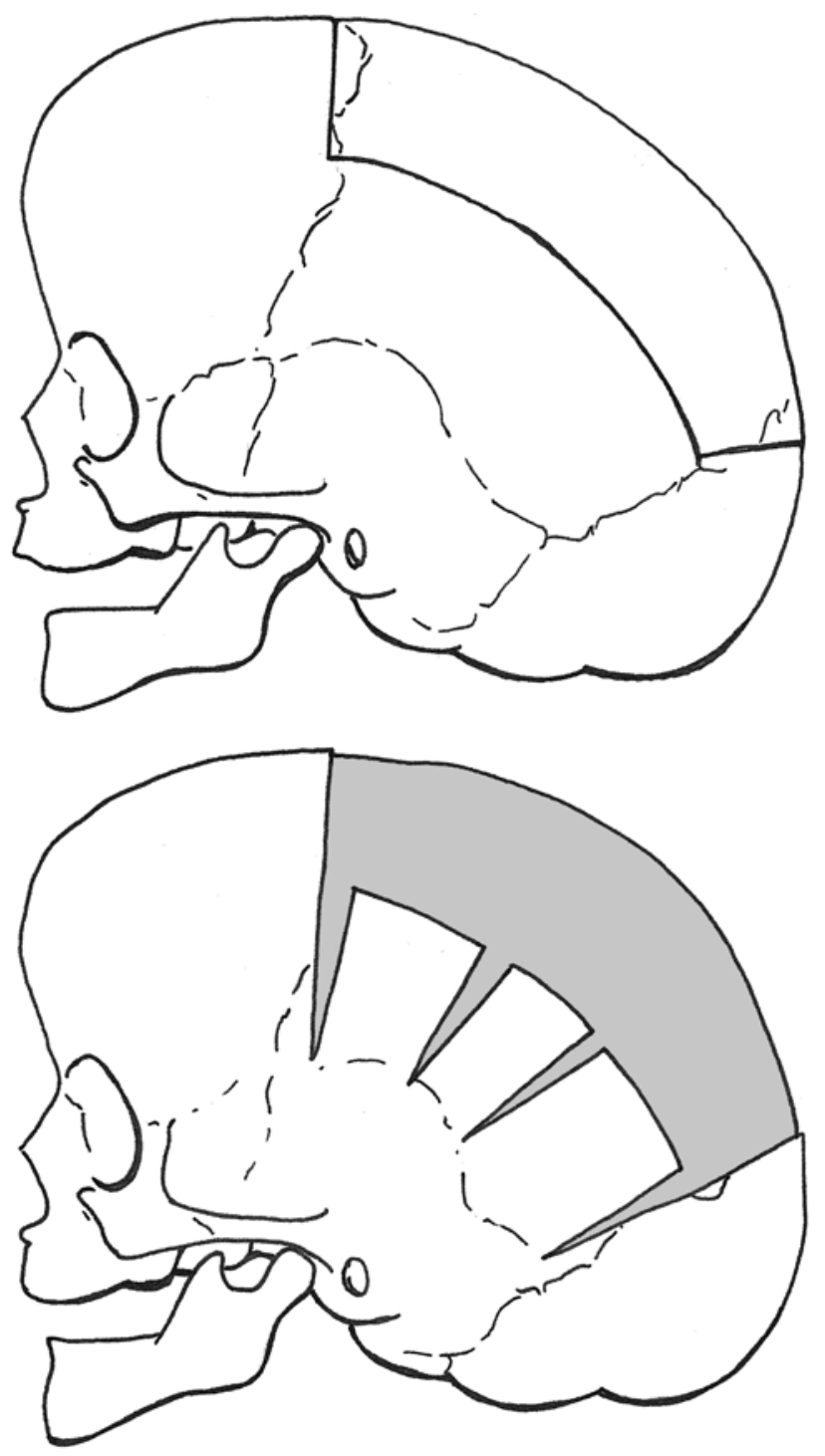

FIG. 1. Modified strip craniectomy with lateral barrel staving. The dura not covered by bone at the end of the procedure is shown in gray. Copyright Gregory P. L. Thomas. Published with permission.

recess the panels, correcting for bossing. The panels are widened by barrel staving. All 4 panels are secured to the skull base with stainless steel wire. The vertex panel is divided, and together with bone fragments created in the shaping of the other panels, placed, without fixation, to cover the vertex expansion gap. These bone pieces are retained in position beneath a pericranial flap (Fig. 2).

Patients with a milder deformity underwent subtotal $\mathrm{CR}$ in which the frontal panel, occipital panel, or both panels were left in situ and flared supralaterally through barrel staving. Panels were left in situ when the deformity affecting that area was judged to be sufficiently mild so as not to warrant correction.

From 2007 MSC was increasingly rarely performed, due to a higher rate of revision surgery in these patients. Instead, children were treated with CR at 12 months of age. The last MSC was performed in 2010. 

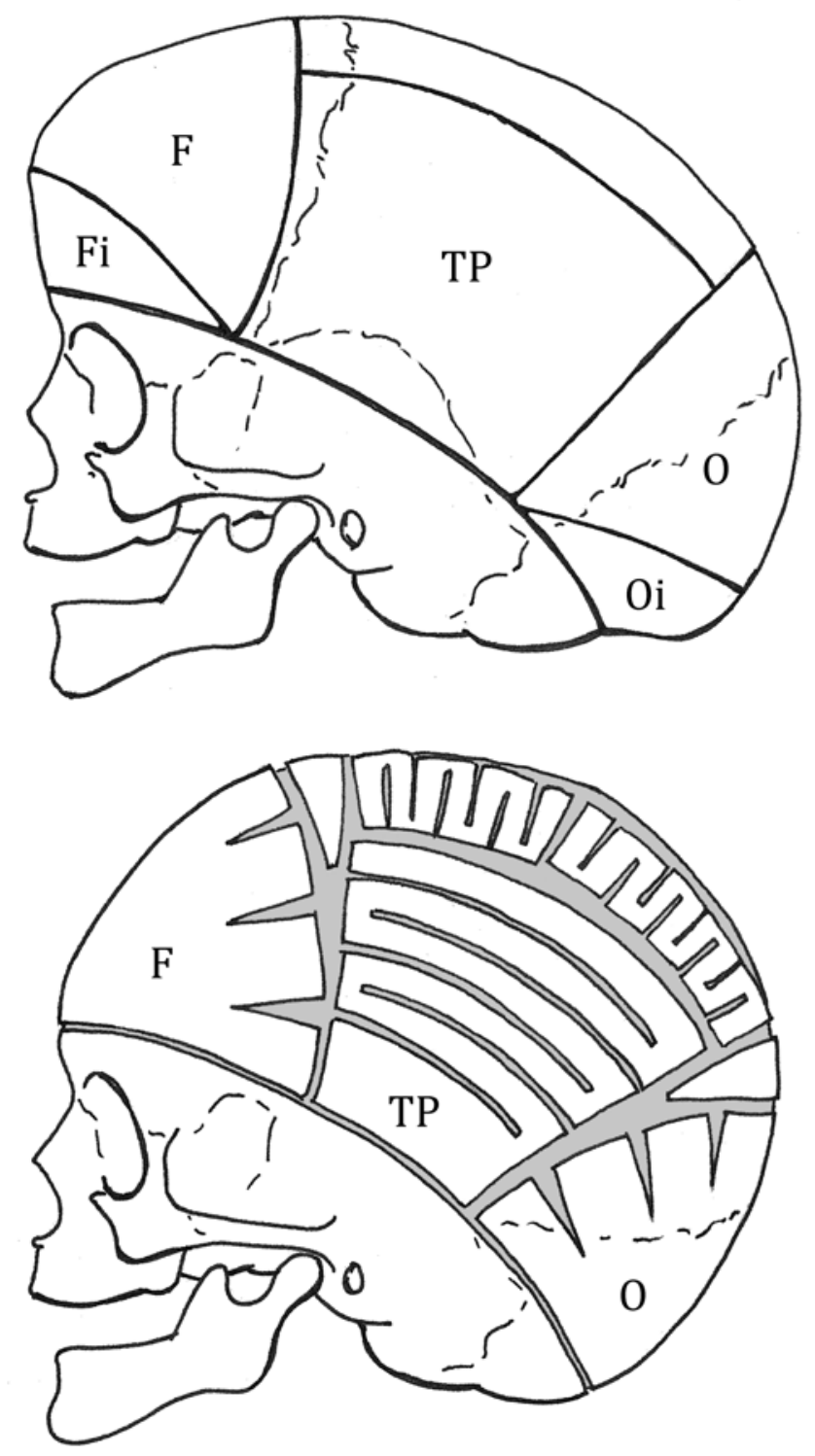

FIG. 2. Total $C R$ procedure; lateral switch rotation technique. The frontal $(\mathrm{F})$ and occipital $(\mathrm{O})$ panels are raised and crescent-shaped strips ( $\mathrm{Fi}$ and $\mathrm{Oi}$ ) are excised to recess the panels, which are widened by barrel staving. Temporoparietal (TP) panels are elevated and interlocking osteotomies are performed to permit lateral expansion. The panels are then either rotated through $180^{\circ}$ in situ or switched from side to side. Copyright Gregory P. L. Thomas. Published with permission.

\section{Follow-Up}

Following discharge patients were reviewed at 3-6 months, then approximately yearly to the age of 10 years, after which they were evaluated on a biannual basis until skeletal maturity. Those patients whose progress raised concerns were followed up on a more frequent basis. All patients were repeatedly reviewed by a multidisciplinary team that included the operative surgeons, a clinical psychologist, an orthoptist (with ophthalmological support), and speech and language therapists. Patients were specifically assessed with regard to the possible presence of raised ICP.
Symptoms considered suggestive of raised ICP included: persistent early morning or nocturnal headaches that awoke a child from sleep; sleep disturbance; nausea or vomiting, especially in conjunction with nocturnal headaches; irritability manifesting as a short attention span, violent outbursts, declining academic performance, and sociability; new onset psychomotor delay not attributable to other causes; deteriorating gait; persistent lethargy; and seizures. In those patients in whom these symptoms were new in onset and other potential causative factors had been excluded, the children were closely followed up for between 3 and 6 months. Follow-up might be extended further if the symptoms were sufficiently mild. If the symptoms persisted or deteriorated over this period, a CT scan with 3D reconstruction of the head was performed.

Signs suggestive of raised ICP were also sought in patients presenting with the symptoms described above. All patients underwent funduscopy, and when papilledema was identified, a CT scan was arranged immediately. Patients who experienced an abnormal cessation of head growth (a "plateau" in head circumference) or who developed an abnormal cranial morphology (including a scaphocephalic relapse, vertex bulge, turricephaly, brachycephaly, or frontal plagiocephaly) were considered likely to be at higher risk of raised ICP. When these morphological abnormalities were present in conjunction with newonset symptoms, CT was expedited. Occasionally CT was performed when morphological deterioration was severe, even in the absence of symptoms.

The CT scans were reported by consultant neuroradiologists with a specialist interest in craniosynostosis and then discussed with a consultant surgical craniofacial team, consisting of pediatric neurosurgeons and plastic and reconstructive surgeons. New radiological signs were considered to be suggestive of raised ICP, including a beaten-copper pattern of the calvaria, reduced extraaxial space, or ventricular effacement. If these were present and believed to be consistent with the clinical symptoms and signs that the patient had manifest, formal ICP monitoring was organized.

Monitoring was conducted over a 24- to 48-hour period using an intraparenchymal Codman microsensor (Codman Microsensor, Johnson \& Johnson Professional Inc.) placed in the right or left frontal lobe under a general anesthetic. A baseline consistently above $15 \mathrm{~mm} \mathrm{Hg}$ or more than $3 \mathrm{~B}$-waves in a 24-hour period was considered to be indicative of raised ICP. ${ }^{50}$

Children with raised ICP underwent calvarial expansion by either lateral panel release or subtotal CR. The patients were closely monitored in situations in which the ICP was considered to be borderline. Further intraparenchymal monitoring was performed at a later date depending on subsequent clinical and radiological findings. All children who underwent repeat transcranial surgery for raised ICP or another indication were reviewed by a clinical geneticist specialist and underwent genetic screening. This study, as a retrospective audit, was performed in compliance with local Institutional Review Board regulations.

\section{Statistical Analysis}

Statistical analysis was performed using the Stata statis- 
tical software package (version 12.1, StataCorp). The primary outcome of interest was whether a patient developed raised ICP following surgery. A secondary outcome was whether the patient underwent formal ICP monitoring following surgery. The primary exposure of interest was type of surgery (CR or MSC). Confounders included age at the time of surgery $(<6,6-12,12-18$, or $>18$ months), sex, and year of surgery (1995-1999, 2000-2004, and 2005-2010 inclusive). Cox proportional hazards regression modeling was used to describe the association between type of surgery, ICP monitoring, and raised ICP following surgery.

\section{Results}

In total, 217 patients (164 boys and 53 girls) underwent either MSC $(n=89)$ or CR $(n=128)$ for primary isolated SC (Table 1). A further 19 patients who had surgery during the study period and otherwise met inclusion criteria were excluded because they did not complete more than 2 years of follow-up. Five patients had their care transferred to another center (4 after MSC, 1 after CR) and 1 died (after CR). The remainder, all of whom underwent CR, continue to be followed up but have yet to attend an outpatient appointment beyond 24 months after their primary procedure.

The 217 patients were followed up for a mean of 86 months (range 24-212 months). MSC-treated infants had surgery at a median of 6.0 months of age (mean $6.0 \pm 1.4$ months, range 2.5-9.5 months; Fig. 3) and were followed up for a mean of 118 months. Children underwent CR at a median age of 17.0 months (mean $26.8 \pm 23.2$ months, range 8.0-139.3 months; Fig. 3) and were then reviewed for a mean of 64 months. Within this group, 67 patients underwent a subtotal CR. The cephalic index of the 2 groups was very similar, with a mean of $67.6 \pm 5.0$ in the MSC-treated group and $67.0 \pm 4.7$ in those who underwent $\mathrm{CR}$.

\section{ICP Monitoring}

In the group treated using $\mathrm{CR}, 21$ children had ICP

\section{TABLE 1. Patient demographics}

\begin{tabular}{lcc}
\hline \multicolumn{1}{c}{ Variable } & MSC $(\%)$ & CR $(\%)$ \\
\hline No. of patients & 89 & 128 \\
\hline Sex & & \\
\hline Female & $14(15.7)$ & $39(30.5)$ \\
\hline Male & $75(84.3)$ & $89(69.5)$ \\
\hline Raised ICP before surgery & $0(0.0)$ & $15(11.7)$ \\
\hline Age at operation (mos) & & \\
\hline$<6$ & $48(53.9)$ & $0(0.0)$ \\
\hline $6-12$ & $41(46.1)$ & $14(10.9)$ \\
\hline$>12$ & $0(0.0)$ & $114(89.1)$ \\
\hline Yr of operation & & $11(8.6)$ \\
\hline $1995-1999$ & $36(40.4)$ & $28(21.9)$ \\
\hline $2000-2004$ & $37(41.6)$ & $89(69.5)$ \\
\hline $2005-2010$ & $16(18.0)$ & $15(11.7)$ \\
\hline ICP monitoring & $28(31.5)$ & $2(1.6)$ \\
\hline Raised ICP after surgery & $13(14.6)$ &
\end{tabular}

monitoring prior to surgery as part of a standard management protocol. ICP monitoring was considered in all patients in whom nonoperative management was proposed or when parents were reluctant to agree to corrective surgery. Children who had ICP monitoring were older on average (mean $66.0 \pm 30.4$ [SD] months, range 21.3-139.3 months) than others undergoing CR (mean $19.1 \pm 10.2$ months, range 8.0-61.8 months). Within this group, 15 children were found to have raised ICP before primary surgery.

In total, 43 patients (19.8\%) had ICP monitoring following primary surgery. Eight presented during follow-up with new symptoms, clinical signs, and radiological signs consistent with raised ICP, 22 had symptoms and radiological signs only, while 7 had symptoms alone (Table 2). The final 6 patients did not present with symptoms but had a significant deterioration in their calvarial shape and signs suggestive of raised ICP on CT. Of the group of 43 patients as a whole, $11(25.6 \%)$ were found to have raised ICP on monitoring.

Twelve patients who did not have raised ICP at their first monitoring procedure subsequently developed new symptoms, or clinical or radiological signs (Table 2), which resulted in these patients undergoing a further ICP monitoring procedure at a mean of 28 months later (range 7-110 months). Four patients (33.4\%) were found to have raised ICP on their second ICP monitoring procedure. Two patients had a third monitoring procedure for further symptoms. Neither was found to have raised ICP.

Although all patients who had ICP monitoring presented with new symptoms or signs indicative of raised ICP, no particular symptom or clinical sign was more closely correlated with the presence of raised ICP on subsequent monitoring (Table 3). Similarly, although patients were usually required to have both positive clinical and radiological findings before undergoing ICP monitoring, no 1 radiological sign correlated better with a later finding of raised ICP than any other (Table 3). Furthermore, in the 8 instances in which ICP monitoring was performed because of highly suggestive clinical symptoms despite a lack of new radiological signs, an elevated ICP was found in only 2 of those children.

A primary Type I Chiari malformation was an incidental finding in 3 patients with suspected raised ICP. In all patients the malformation was present on initial imaging and had not progressed since. It was not considered to be a sign of raised ICP. All 3 children proved to have a normal ICP on monitoring. Of all the ICP monitoring procedures performed, only 1 was abandoned without a usable record following probe malfunction shortly after insertion. The patient underwent a repeat ICP monitor insertion the following day, which proceeded without incident.

\section{Elevated ICP}

In total, 15 patients proved to have an elevated ICP on monitoring (Table 4). This elevated ICP was diagnosed at a mean age of 60 months, at a mean interval of 51 months after primary surgery (range 23-100 months). The age of the patients, and the interval following surgery at which patients who were found to have a normal ICP underwent monitoring, were very similar to that for children with 


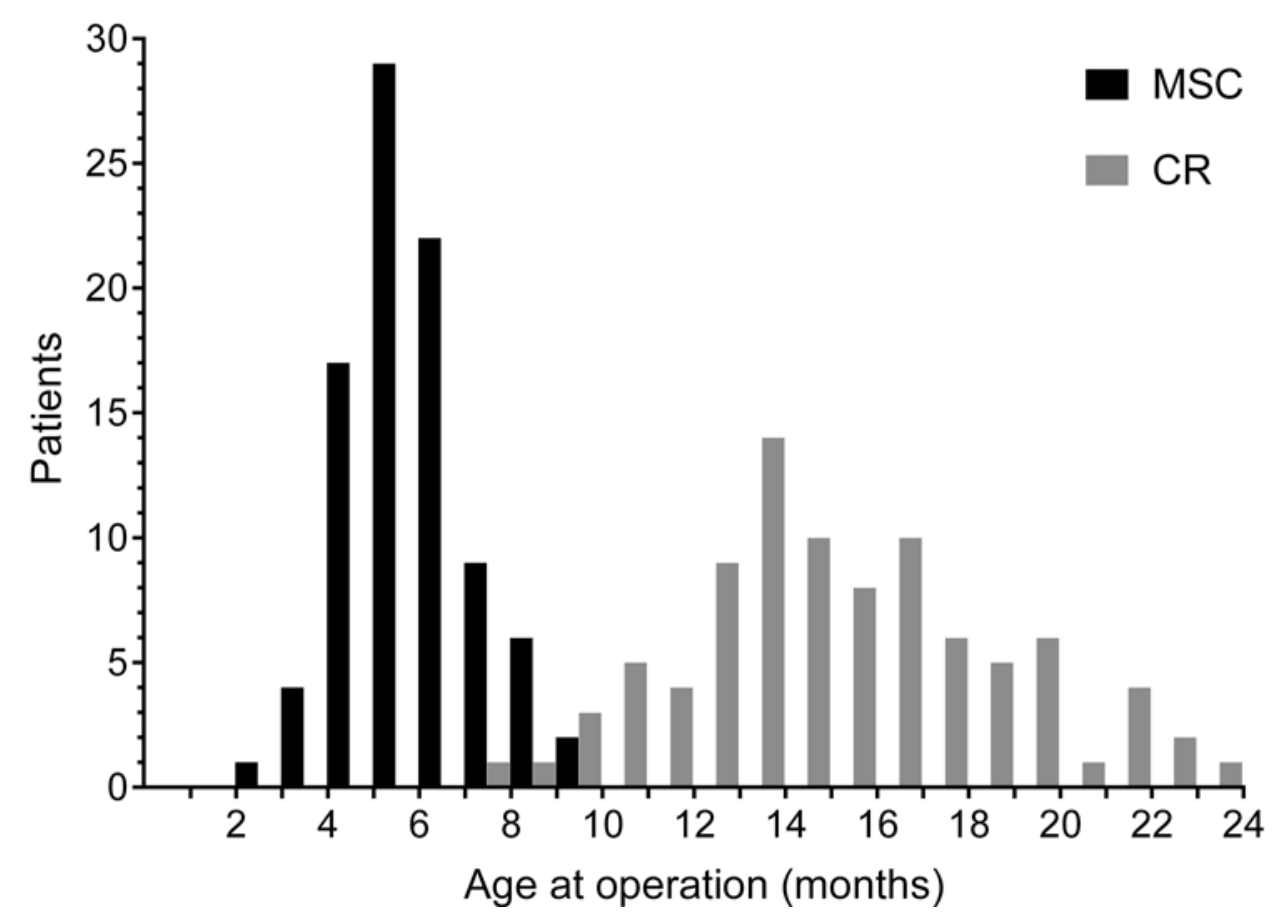

FIG. 3. Histogram of patient age (months) at the time of primary surgery for the first 24 months. A further $38 \mathrm{CR}$-treated patients underwent their primary surgery between 24 and 140 months of age.

raised ICP. These patients with proven raised ICP underwent a CR or expansion procedure (Table 4).

A further 5 patients underwent a secondary CR procedure to correct a poor morphological outcome. Two of these patients had undergone postoperative ICP monitoring, which was normal in 1 patient and borderline in the other. One other child required the repair of a persistent calvarial vertex defect 9 years after their primary MSC. All 6 patients who had a secondary procedure for an in- dication other than raised ICP had a primary MSC. Overall, $19(21.3 \%)$ of 89 MSC patients underwent a second unplanned transcranial procedure, while only $2(1.6 \%)$ of $128 \mathrm{CR}$ patients did, excluding ICP monitoring procedures ( $p<0.0001$, Fisher exact test).

Significant intraoperative venous sinus hemorrhages occurred in 2 MSC patients (2.2\%; all in the sagittal sinus) and $6 \mathrm{CR}$ patients $(4.7 \%$; 3 in the sagittal sinus, 2 in the superior petrosal sinus, and 1 in the transverse sinus). In

TABLE 2. Presence of new symptoms, clinical signs, and radiological signs leading to ICP monitoring by episode

\begin{tabular}{|c|c|c|c|c|c|c|}
\hline $\begin{array}{l}\text { ICP Monitoring } \\
\text { Episode }\end{array}$ & $\begin{array}{c}\text { No. of } \\
\text { Patients }\end{array}$ & $\begin{array}{l}\text { New Clinical } \\
\text { Symptoms }\end{array}$ & $\begin{array}{l}\text { New Clinical } \\
\text { Signs }\end{array}$ & $\begin{array}{l}\text { New Radiological } \\
\text { Signs }\end{array}$ & $\begin{array}{l}\text { No. w/ Raised } \\
\text { ICP (\%) }\end{array}$ & $\begin{array}{l}\text { No. w/ Repeat ICP } \\
\text { Monitoring* }^{*}\end{array}$ \\
\hline \multicolumn{7}{|l|}{ First } \\
\hline & 8 & Yes & Yes & Yes & $2(25.0)$ & 2 \\
\hline & 22 & Yes & No & Yes & $6(27.3)$ & 6 \\
\hline & $7 \dagger$ & Yes & No & No & $2(28.6)$ & 1 \\
\hline & 6 & No & Yes & Yes & $1(16.7)$ & $3 \ddagger$ \\
\hline Total & 43 & & & & $11(25.6)$ & 12 \\
\hline \multicolumn{7}{|l|}{ Second } \\
\hline & 2 & Yes & Yes & Yes & $1(50.0)$ & 1 \\
\hline & 6 & Yes & No & Yes & $3(50.0)$ & 0 \\
\hline & $3 \dagger$ & Yes & No & No & 0 & 0 \\
\hline & 1 & No & Yes & Yes & 0 & 1 \\
\hline Total & 12 & & & & 4 (33.4) & 2 \\
\hline \multicolumn{7}{|c|}{$\begin{array}{l}\text { *epeat ICP monitoring was only performed in patients who did not have raised ICP on that episode and then presented with new symptoms } \\
\text { or signs. } \\
\text { † One patient in both the first and second ICP monitoring episode did not undergo CT. } \\
\text { † One patient had a borderline ICP on the first ICP monitoring episode and therefore underwent repeat monitoring } 6 \text { months later (which } \\
\text { proved normal) without developing new symptoms or signs. This patient later developed new symptoms and radiological signs and underwent a } \\
\text { further ICP monitoring episode (counted in the second ICP monitoring episode section of the table). }\end{array}$} \\
\hline
\end{tabular}


TABLE 3. Presenting symptoms and signs of patients who had ICP monitoring following primary surgery*

\begin{tabular}{|c|c|c|}
\hline Symptoms & Total & $\begin{array}{c}\text { No. w/ Raised } \\
\text { ICP }(\%)\end{array}$ \\
\hline \multicolumn{3}{|l|}{ Clinical Symptoms } \\
\hline Deteriorating gait & 1 & $0(0.0)$ \\
\hline Headache & 23 & $7(30.4)$ \\
\hline Irritability & 28 & $8(28.6)$ \\
\hline Lethargy & 1 & $0(0.0)$ \\
\hline Nausea & 4 & $1(25.0)$ \\
\hline Psychomotor delay & 10 & $2(20.0)$ \\
\hline Seizures & 1 & $0(0.0)$ \\
\hline Sleep disturbance & 4 & $1(25.0)$ \\
\hline None & 7 & $1(14.3)$ \\
\hline \multicolumn{3}{|l|}{ Clinical signs } \\
\hline Plateau in head circumference & 4 & $1(25.0)$ \\
\hline Brachycephaly & 1 & $1(100.0)$ \\
\hline Frontal plagiocephaly & 1 & $1(100.0)$ \\
\hline Scaphocephaly & 6 & $1(16.7)$ \\
\hline Turricephaly & 1 & $0(0.0)$ \\
\hline Vertex bulge & 8 & $3(37.5)$ \\
\hline Papilledema & 1 & $1(100.0)$ \\
\hline \multicolumn{3}{|l|}{ Radiological signs } \\
\hline Beaten-copper pattern & 35 & $11(31.4)$ \\
\hline Reduced extraaxial space & 35 & $9(25.7)$ \\
\hline Ventricular effacement & 8 & $3(37.5)$ \\
\hline None & 8 & $2(25.0)$ \\
\hline
\end{tabular}

* Patients may manifest 1 or more symptoms or signs. No single symptom or sign was more or less likely to predict raised ICP (all p values nonsignificant, Fisher exact test).

addition, $6 \mathrm{CR}$ patients (4.6\%) experienced intraoperative subdural hemorrhages that required a durotomy for control. Clinically insignificant dural breaches also occurred more frequently during $\mathrm{CR}$ procedures.

\section{Predictors of Raised ICP}

Unadjusted Cox regression models showed that patients treated by MSC were at increased risk of raised ICP following surgery (hazard ratio [HR] 6.1, 95\% CI 1.4-27.1; Table 5). Overall 13 MSC-treated patients (14.6\%) developed raised ICP, while only 2 patients $(1.6 \%)$ treated by CR did. Both CR-treated patients had a subtotal CR. There was also an effect of age at time of surgery, with patients older than 12 months having a lower risk of raised ICP ( $p$ $=0.01$ ). Patients undergoing MSC had a longer follow-up period than CR-treated children. Therefore, a sensitivity analysis including only patients operated on prior to 2005 was performed to ensure patients in both surgical groups had adequate follow-up time to allow for the development of raised ICP. After this analysis, the findings remained unchanged for the comparisons of MSC versus CR (HR $=6.4,95 \%$ CI $0.83-49.9 ; \mathrm{p}=0.075)$ and age $>18$ months versus $<6$ months (HR 0.12, 95\% CI 0.02-0.96; $p=0.046$ ).

Given the high correlation between age at surgery and type of procedure, it is not possible statistically to reliably determine which factor is causal in relation to raised ICP. However, all children older than 12 months at the time of surgery only underwent CR, and this group had a significantly lower risk of raised ICP. Furthermore, no child older than 18 months at surgery developed raised ICP. Also, no children with proven raised ICP prior to surgery, all of whom were then treated by $\mathrm{CR}$, were found to develop it subsequently, despite the fact that $7(46.7 \%)$ of these 15 patients had ICP monitoring after surgery.

Within the MSC group, the age at operation of patients who later developed raised ICP (mean $6.0 \pm 1.4$ months, median 5.6 months) was almost identical to that of children who did not (mean $6.0 \pm 1.4$ months, median 6.0 months), suggesting that age at surgery was not a significant factor within that group. In the CR group, the age at operation of the 2 patients who developed raised ICP was 11.6 months and 14.5 months. These ages were lower than the mean $(27.0 \pm 23.3$ months $)$ and median (17.1 months) of the rest of the group, but were not significantly different (Mann-Whitney U-test, $\mathrm{p}=0.17$ ). Thus, age at operation may possibly be a significant factor in CR-treated patients.

Regression modeling showed that there was no significant difference in ICP monitoring rates between the MSC- and CR-treated groups (HR 1.7, 95\% CI 0.9-3.3; $\mathrm{p}=0.083)$. However, patients treated by total CR did require monitoring less often than either MSC (HR 5.7, 95\% CI 1.3-24.0; $\mathrm{p}=0.018$ ) or subtotal CR-treated patients (HR 5.2, 95\% CI 1.2-22.9; $p=0.031$ ). While more MSC-treated patients eventually experienced raised ICP, many fewer subtotal CR-treated patients did. The effect of high levels of monitoring in subtotal CR-treated patients remained significant after adjusting for age at operation. All patients who had raised ICP before surgery and had ICP monitoring following surgery were treated by subtotal CR. No other factors proved to be significant predictors of postoperative raised ICP.

\section{Discussion}

The overall incidence of raised ICP following corrective surgery for SC in this study was 6.9\%; among MSCtreated patients the rate was $14.6 \%$. This is higher than the $1.4 \%-3.8 \%$ rate reported in other series of patients undergoing strip craniectomy. ${ }^{1,47}$ However, the manner in which patients with potentially raised ICP were identified differs between this study and the others. In the series of Adamo and Pollack, 2 patients underwent further surgery, having both presented with papilledema. ${ }^{1}$ In 1 case this was associated with restricted head growth and in the other, new-onset bicoronal craniosynostosis. Both patients had an elevated ICP on lumbar puncture.

In our series, 20 patients manifested worsening head shape as one of their presenting features, of whom 7 had raised ICP. Interestingly, the 2 patients who developed secondary synostosis of previously uninvolved coronal sutures (right and bicoronal) both had an elevated ICP.

In the series of van Veelan and colleagues, 6 patients were found to have papilledema, 3 of whom were found to have raised ICP. ${ }^{47}$ Papilledema is a relatively late sign of low sensitivity in children younger than 8 years old. ${ }^{45}$ In 
TABLE 4. Patients with proven raised ICP after surgery

\begin{tabular}{|c|c|c|c|c|c|c|c|}
\hline $\begin{array}{c}\text { Case } \\
\text { No. }\end{array}$ & $\begin{array}{c}\text { Age at Primary } \\
\text { Transcranial Procedure } \\
\text { (mos), Sex }\end{array}$ & $\begin{array}{l}\text { Primary } \\
\text { Transcranial } \\
\text { Procedure }\end{array}$ & $\begin{array}{l}\text { No. ICP } \\
\text { Monitoring } \\
\text { Procedures }\end{array}$ & $\begin{array}{l}\text { Age at Raised } \\
\text { ICP Diagnosis } \\
\text { (mos) }\end{array}$ & $\begin{array}{c}\text { Interval Btwn 1st } \\
\text { Procedure to Raised } \\
\text { ICP Diagnosis (mos) }\end{array}$ & $\begin{array}{l}\text { Secondary } \\
\text { Transcranial } \\
\text { Procedure }\end{array}$ & $\begin{array}{l}\text { ICP Monitoring After } \\
\text { 2nd Transcranial } \\
\text { Procedure }\end{array}$ \\
\hline 1 & $4.5, \mathrm{M}$ & MSC & 1 & 75 & 70 & TCR-P & NP \\
\hline 2 & 4.6, M & MSC & 1 & 38 & 34 & TCR-A-P & NP \\
\hline 3 & 4.7, M & MSC & 1 & 60 & 55 & TCR-A-P & NP \\
\hline 4 & $4.9, \mathrm{M}$ & MSC & 1 & 48 & 44 & TCR-A-P & NP \\
\hline 5 & $5.4, \mathrm{M}$ & MSC & 1 & 56 & 50 & TCR-A-P & NP \\
\hline 6 & $5.5, \mathrm{M}$ & MSC & 1 & 31 & 25 & CE & NP \\
\hline 7 & $5.6, F$ & MSC & 1 & 47 & 42 & TCR-A-P & NP \\
\hline 8 & $5.8, \mathrm{M}$ & MSC & 2 & 73 & 67 & TCR-A & NP \\
\hline 9 & $6.0, \mathrm{M}$ & MSC & 2 & 49 & 43 & CE & NP \\
\hline 10 & $6.4, \mathrm{M}$ & MSC & 1 & 54 & 48 & TCR-A-P & NP \\
\hline 11 & 7.0, M & MSC & 1 & 30 & 23 & TCR-A-P & NP \\
\hline 12 & $8.5, \mathrm{M}$ & MSC & 2 & 91 & 43 & TCR-A-P & Normal \\
\hline 13 & $8.8, M$ & MSC & 2 & 108 & 100 & TCR-A-P & NP \\
\hline 14 & $11.6, F$ & TCR-A & 1 & 50 & 39 & CE & NP \\
\hline 15 & $14.5, \mathrm{M}$ & TCR-P & 1 & 95 & 80 & CE & NP \\
\hline
\end{tabular}

CE = calvarial expansion by lateral-panel release; NP = not performed; TCR-A = subtotal calvarial remodeling with the anterior (frontal) panel retained in situ; TCR-A-P = subtotal calvarial remodeling with both panels retained in situ with only the parietal and vertex panels raised and remodeled; TCR-P = subtotal calvarial remodeling with the posterior (occipital) panel retained in situ.

our patient series only 1 child had papilledema, because we believe a vigilant follow-up protocol was able to identify cases with raised ICP before papilledema developed.

In a smaller series of 47 patients with $\mathrm{SC}$, Cetas and colleagues reported postoperative raised ICP in 5 patients (10.5\%), 2 of whom had strip craniectomies with barrel staving and 3 an anterior two-thirds cranial vault reconstruction. ${ }^{8}$ This rate more closely reflects that of this series. All of their patients presented with symptoms of raised ICP and 3 had papilledema. Interestingly, all 5 were found to have secondary unicoronal or bicoronal synostosis. They also report that all patients showed a decreasing velocity of head growth relative to the normal population, with percentiles for head circumference decreasing between their first and second procedures. The clinical significance of this finding is questionable, as the phenomena of postsurgical decline in relative head circumference in $\mathrm{SC}$ is well recognized and widespread: ${ }^{12,44,47}$ it is therefore probably unlikely to have a specific etiological role in the development of raised ICP.

In our study, patients only underwent ICP monitoring if the exhibited symptoms or signs of raised ICP and, in the majority, had corresponding radiological signs. However, within this group of children, no single or combination of symptoms, clinical signs, or radiological findings were significantly more likely to herald raised ICP. Eide

TABLE 5. Cox regression model of predictors of raised ICP

\begin{tabular}{lcccc}
\hline Characteristic & No Raised ICP $(\%)$ & Raised ICP $(\%)$ & HR $(95 \%$ Cl $)$ & p Value \\
\hline No. of patients & 202 & 15 & & \\
\hline Sex & & & & \\
\hline Female & $51(96.2)$ & $2(3.8)$ & $1.9(0.4-8.3)$ & 0.408 \\
\hline Male & $151(92.1)$ & $13(7.9)$ & & 0.226 \\
\hline Age at operation (mos) & & & Reference & 0.011 \\
\hline$<6$ & $39(81.3)$ & $9(18.8)$ & $0.5(0.2-1.5)$ & \\
\hline $6-12$ & $50(90.9)$ & $5(9.1)$ & $0.1(0.0-0.5)$ & 0.076 \\
\hline$>12$ & $113(99.1)$ & $1(0.9)$ & & 0.137 \\
\hline Yr of operation & & & Reference & \\
\hline $1995-1999$ & $39(83.0)$ & $8(17.0)$ & $0.3(0.1-1.1)$ & $0.4(0.1-1.4)$ \\
\hline $2000-2004$ & $61(93.8)$ & $4(6.2)$ & Reference & 0.018 \\
\hline $2005-2010$ & $102(97.1)$ & $3(2.9)$ & $6.1(1.4-27.1)$ & \\
\hline CR & $126(98.4)$ & $2(1.6)$ & $13(14.6)$ & \\
\hline MSC & $76(85.4)$ & & & \\
\hline
\end{tabular}


and colleagues, in a large series of 121 children, reported that there was little correlation between particular clinical symptoms and an abnormal ICP. ${ }^{11}$ We suspect that this is because the typical symptoms of elevated ICP, including headaches and irritability, have a number of potential causes in children with craniosynostosis, and are therefore poorly specific. Likewise, although a beaten-copper appearance of the calvaria on radiological imaging has long been associated with raised ICP, it is common following surgery for SC, and increases in incidence with patient age. ${ }^{4,46}$ Similarly, reduction of the extraaxial space on CT, manifesting as effacement of the sulci and loss of the subarachnoid space, is more common in children with raised ICP, but is also present in those with normal pressures. ${ }^{46}$ Furthermore, the identification of 2 patients with abnormal ICP but no corresponding signs on CT underscores the point made by Tuite and colleagues that radiological signs are neither specific nor sensitive in this regard ${ }^{46}$ We therefore conclude that once raised ICP is suspected, only formal monitoring can determine for certain whether it is present. We prefer to perform direct monitoring of ICP using an intraparenchymal Codman microsensor. Although this method requires a general anesthetic for probe placement, it has consistently proved to be a highly reliable and reproducible method of assessing ICP, with only an infrequent and minor complication rate associated with it. ${ }^{11,22,33,50}$ In this patient series, the only significant complication was probe malfunction, necessitating a repeat procedure. Our use of a threshold of more than $15 \mathrm{~mm} \mathrm{Hg}$ to define an abnormally elevated ICP is consistent with that used by all previous studies that have undertaken overnight intracranial ICP monitoring in craniosynostosis, no matter whether an extradural or subdural device was employed. ${ }^{6,11,13,28,35,42,43,45,46}$ The pathological significance of multiple B-type waves is also well recognized in the literature. ${ }^{11,35,50}$ Consistent with the patient series of van Veelan et al. and Cetas et al., we found that elevated ICP was diagnosed late, at least 2 years after primary surgery, with a mean at just under 4.5 years of follow-up. ${ }^{8,47}$ This interval, along with the findings that only 1 patient had papilledema and that 4 children developed raised ICP on re-monitoring after a proven normal ICP, strongly suggests that the pathological rise in ICP we observed occurred after primary surgery. We have no evidence to indicate that an elevated ICP was present beforehand and persisted through the first corrective procedure to the time of diagnosis after surgery in any patients in this study. The insidious onset of raised ICP following corrective surgery underscores the need for prolonged, careful follow-up.

The pathological evolution of intracranial hypertension in CS is not well described, not least because, except in a handful of cases, it is treated when diagnosed. ${ }^{6}$ A dearth of evidence of significant impairments due to raised ICP in patients re-presenting late after surgery would suggest that in SC it rarely reaches a catastrophic conclusion. However, raised ICP may well account for some of the subtle behavioral and developmental abnormalities encountered in SC, and prevent individuals from attaining their full intellectual potential. The extent to which raised ICP is responsible for these neurobehavioral abnormali- ties is contested. ${ }^{14}$ Studies that infer that there is little or no relationship between the two often compare pre- and postoperative developmental outcomes or children that have or have not had surgery., 9,20,38,39 The conclusions that these studies reach are in part based on the implicit assumption that early surgery corrects raised ICP where present and prevents its future occurrence. The data presented here contradict this assumption and suggest that any developmental or psychomotor assessment not accompanied by contemporary ICP measurements should be interpreted with caution.

In this study raised ICP was significantly more likely to be diagnosed following MSC than CR. Not only was raised ICP significantly less common following CR surgery, no patient with proven intracranial hypertension prior to surgery and treated by CR developed it subsequently. Patients with a preoperative diagnosis of raised ICP had ICP monitoring more frequently than others after surgery, as the multidisciplinary team had a lower threshold for monitoring in these patients.

We hypothesize that MSC inadequately decompresses the cranium and incompletely corrects the scaphocephalic deformity, failing to prevent raised ICP from developing in a minority of cases. Morphological outcome studies indicate that variants of open vertex strip craniectomy often result in a residual scaphocephalic deformity, with a cephalic index ranging from 70 to 74 , frequently below the population norm..$^{2,5,19,29,31,47}$ Calvarial remodeling, by contrast, as a more extensive procedure allows a comprehensive correction of the deformity, which usually returns the cephalic index to the normal population mean. . $^{15,26,40,44}$

We do not believe that raised ICP can simply be attributed to a poor morphological outcome in a minority of cases in an otherwise successful procedure. In data we have presented elsewhere, we found that the preoperative and immediate postoperative head circumference and cephalic index of patients who developed an abnormal ICP were indistinguishable from other patients treated by the same technique.

Early restenosis of the sagittal suture has been implicated in the development of intracranial hypertension. ${ }^{1,3,8}$ In our unit we do not perform serial radiological investigations in asymptomatic postoperative children, to minimize their radiation exposure. Therefore, we cannot comment as to whether early restenosis occurred in this series. However, a wide vertex strip was taken in the MSC technique employed, with the intention of preventing its occurrence. By the time patients were re-imaged, at least 18 months after surgery, it was typical to find new bone formation at previous osteotomy and craniectomy sites.

Over the last decade many craniofacial units have adopted minimal access, endoscopic, or spring-assisted approaches to correcting $\mathrm{SC}$, in part in an attempt to avoid the morbidity and cost perceived to be associated with total CR techniques, ${ }^{7,10,17,18,30,37,41,48,52}$ The incidence of postoperative intracranial hypertension with these procedures has yet to be reported. In broad terms, these approaches appear to result in better morphological outcomes than open vertex strip craniectomy procedures, with cephalic indices within the normal range. ${ }^{7,10,18,30,37,41}$ If the correction of the scaphocephalic deformity is an important 
determinant of the development of raised ICP, then one might expect these techniques to have a similar postoperative incidence to that we report for CR. However, we do not understand the mechanism by which intracranial hypertension arises in SC following surgery. Postoperative interventions that constrain cranial expansion following surgery, such as helmet therapy, might inadvertently increase the incidence of raised ICP.

In addition to the primary procedure, we also identified a relationship between age at primary surgery and the development of raised ICP postoperatively. Because of the close correlation between age at operation and surgical procedure (Fig. 3) we were unable to determine which factor of the two was more significant. However, in the MSC group, the age at operation of those who later developed raised ICP was essentially the same as those who did not, indicating that age is unlikely to be a significant factor within this group. Conversely, in the CR group the 2 patients who suffered raised ICP following surgery were both younger than the group mean and median, which does not discount the possibility that age might still be a significant factor with this procedure. Performing CR procedures in infants of a similar age to the MSC group would be likely to provide data that would resolve this question, although justifying doing so would be difficult.

During the latter part of the series presented here, our unit abandoned the MSC procedure because of a growing realization that reoperation rates were higher following MSC than CR, and that morphological outcomes were generally less satisfactory. In this study the MSC cohort had an overall major transcranial reoperation rate of $21.3 \%$, including both ICP and morphological indications, as compared with a $1.6 \%$ rate for $\mathrm{CR}$ (excluding minor ICP monitoring procedures in both groups).

We accept that CR entails longer admissions and greater transfusion rates than MSC, ${ }^{25}$ and is liable to a higher incidence of accidental vascular or dural breach, as is inevitable with the more extensive dissection that the procedure demands. However, we consider that it is undesirable to expose patients to a procedure, the MSC, which still has attendant risks, ${ }^{25,27}$ is less effective at correcting the scaphocephalic deformity, and has a markedly higher reoperation rate, with the risks that that entails. The significantly higher rate of raised ICP experienced by these patients postoperatively is a further cause of concern.

The question arises as to whether the 2 surgical cohorts presented here originate from the same population. In our estimation they do. The severity of disease, as measured by the cephalic index, is very similar between the 2 groups. Patient selection was strictly conducted to exclude all but those who had what was considered to be an isolated, nonsyndromic SC. In total 11 patients were excluded. Two had syndromes known to be associated with craniosynostosis, 4 had chromosomal abnormalities, 3 had mutations of genes associated with craniosynostosis, and 2 had sagittal synostosis secondary to intraventricular hemorrhage and CSF shunting. The only factor that separates the two groups, and decided which operation a child underwent, was the age at which they were first examined by the Unit. Variations in age at which primary healthcare teams make the initial diagnosis, and the efficacy of the referral route then pursued, inevitably occur with a relatively rare condition managed by a supraregional unit, such as in this situation. This study's data does not support the notion that more severe cases presented earlier and thus were more likely to undergo MSC.

\section{Conclusions}

The overall rate of raised ICP following corrective surgery for SC was $6.9 \%$ in this series of 217 patients. This incidence was affected by age and surgical approach, with raised ICP significantly more common in patients treated by MSC, at an age of 9 months or younger (14.6\%), rather than older children treated by CR $(1.6 \% ; p=0.018)$. The onset of raised ICP following surgery was insidious. It was confirmed in patients on average over 4 years after surgery, but as late as more than 8 years afterward. Once it was suspected, clinical findings and radiological investigations did not reliably predict its presence. Therefore, patients who have been treated for SC should be enrolled in long-term follow-up regimens that actively screen for raised ICP.

\section{Acknowledgments}

We wish to thank all the members of the Oxford Craniofacial Unit team for their assistance throughout this study.

\section{References}

1. Adamo MA, Pollack IF: A single-center experience with symptomatic postoperative calvarial growth restriction after extended strip craniectomy for sagittal craniosynostosis. J Neurosurg Pediatr 5:131-135, 2010

2. Agrawal D, Steinbok P, Cochrane DD: Long-term anthropometric outcomes following surgery for isolated sagittal craniosynostosis. J Neurosurg 105 (5 Suppl):357-360, 2006

3. Agrawal D, Steinbok P, Cochrane DD: Reformation of the sagittal suture following surgery for isolated sagittal craniosynostosis. J Neurosurg 105 (2 Suppl):115-117, 2006

4. Agrawal D, Steinbok P, Cochrane DD: Significance of beaten copper appearance on skull radiographs in children with isolated sagittal synostosis. Childs Nerv Syst 23:1467-1470, 2007

5. Alvarez-Garijo JA, Cavadas PC, Vila MM, Alvarez-Llanas A: Sagittal synostosis: results of surgical treatment in 210 patients. Childs Nerv Syst 17:64-68, 2001

6. Arnaud E, Renier D, Marchac D: Prognosis for mental function in scaphocephaly. J Neurosurg 83:476-479, 1995

7. Berry-Candelario J, Ridgway EB, Grondin RT, Rogers GF, Proctor MR: Endoscope-assisted strip craniectomy and postoperative helmet therapy for treatment of craniosynostosis. Neurosurg Focus 31(2):E5, 2011

8. Cetas JS, Nasseri M, Saedi T, Kuang AA, Selden NR: Delayed intracranial hypertension after cranial vault remodeling for nonsyndromic single-suture synostosis. J Neurosurg Pediatr 11:661-666, 2013

9. Da Costa AC, Anderson VA, Holmes AD, Lo P, Wray AC, Chong DK, et al: Longitudinal study of the neurodevelopmental characteristics of treated and untreated nonsyndromic craniosynostosis in infancy. Childs Nerv Syst 29:985-995, 2013

10. David LR, Plikaitis CM, Couture D, Glazier SS, Argenta LC: Outcome analysis of our first 75 spring-assisted surgeries for scaphocephaly. J Craniofac Surg 21:3-9, 2010

11. Eide PK, Helseth E, Due-Tønnessen B, Lundar T: Assessment 
of continuous intracranial pressure recordings in childhood craniosynostosis. Pediatr Neurosurg 37:310-320, 2002

12. Fearon JA, McLaughlin EB, Kolar JC: Sagittal craniosynostosis: surgical outcomes and long-term growth. Plast Reconstr Surg 117:532-541, 2006

13. Gault DT, Renier D, Marchac D, Jones BM: Intracranial pressure and intracranial volume in children with craniosynostosis. Plast Reconstr Surg 90:377-381, 1992

14. Hankinson TC, Fontana EJ, Anderson RC, Feldstein NA: Surgical treatment of single-suture craniosynostosis: an argument for quantitative methods to evaluate cosmetic outcomes. J Neurosurg Pediatr 6:193-197, 2010

15. Heller JB, Heller MM, Knoll B, Gabbay JS, Duncan C, Persing JA: Intracranial volume and cephalic index outcomes for total calvarial reconstruction among nonsyndromic sagittal synostosis patients. Plast Reconstr Surg 121:187-195, 2008

16. Horínek D, Hoza D, Tomek A, Hort J, Häckel M, Tichý M: Lumbar pressure and transcranial Doppler sonography in children with scaphocephaly. Br J Neurosurg 22:219-223, 2008

17. Jimenez DF: Editorial. Endoscopes and helmets: yes or no? J Neurosurg Pediatr 9:219-221, 2012

18. Jimenez DF, Barone CM, McGee ME, Cartwright CC, Baker CL: Endoscopy-assisted wide-vertex craniectomy, barrel stave osteotomies, and postoperative helmet molding therapy in the management of sagittal suture craniosynostosis. $\mathbf{J}$ Neurosurg 100 (5 Suppl Pediatrics):407-417, 2004

19. Kandasamy J, Anderson K, Dunne J, Grogan J, Duncan C, Sinha A, et al: Treatment of scaphocephaly with combined vertex craniectomy and bilateral microbarrel staving. J Craniofac Surg 22:42-46, 2011

20. Kapp-Simon KA: Mental development and learning disorders in children with single suture craniosynostosis. Cleft Palate Craniofac J 35:197-203, 1998

21. Kolar JC: An epidemiological study of nonsyndromal craniosynostoses. J Craniofac Surg 22:47-49, 2011

22. Koskinen LO, Olivecrona M: Clinical experience with the intraparenchymal intracranial pressure monitoring Codman MicroSensor system. Neurosurgery 56:693-698, 2005

23. Lajeunie E, Le Merrer M, Bonaïti-Pellie C, Marchac D, Renier D: Genetic study of scaphocephaly. Am J Med Genet 62:282-285, 1996

24. Marucci DD, Johnston CP, Anslow P, Jayamohan J, Richards PG, Wilkie AO, et al: Implications of a vertex bulge following modified strip craniectomy for sagittal synostosis. Plast Reconstr Surg 122:217-224, 2008

25. Maugans TA, McComb JG, Levy ML: Surgical management of sagittal synostosis: a comparative analysis of strip craniectomy and calvarial vault remodeling. Pediatr Neurosurg 27:137-148, 1997

26. Metzler P, Zemann W, Jacobsen C, Grätz KW, Obwegeser JA: Postoperative cranial vault growth in premature sagittal craniosynostosis. J Craniofac Surg 24:146-149, 2013

27. Meyer P, Renier D, Arnaud E, Jarreau MM, Charron B, Buy $\mathrm{E}$, et al: Blood loss during repair of craniosynostosis. Br J Anaesth 71:854-857, 1993

28. Morritt DG, Yeh FJ, Wall SA, Richards PG, Jayamohan J, Johnson D: Management of isolated sagittal synostosis in the absence of scaphocephaly: a series of eight cases. Plast Reconstr Surg 126:572-580, 2010

29. Murray DJ, Kelleher MO, McGillivary A, Allcutt D, Earley MJ: Sagittal synostosis: a review of 53 cases of sagittal suturectomy in one unit. J Plast Reconstr Aesthet Surg 60:991-997, 2007

30. Mutchnick IS, Maugans TA: Nonendoscopic, minimally invasive calvarial vault remodeling without postoperative helmeting for sagittal synostosis. J Neurosurg Pediatr 9:222-227, 2012
31. Panchal J, Marsh JL, Park TS, Kaufman B, Pilgram T, Huang SH: Sagittal craniosynostosis outcome assessment for two methods and timings of intervention. Plast Reconstr Surg 103:1574-1584, 1999

32. Pollack IF, Losken HW, Biglan AW: Incidence of increased intracranial pressure after early surgical treatment of syndromic craniosynostosis. Pediatr Neurosurg 24:202-209, 1996

33. Pople IK, Muhlbauer MS, Sanford RA, Kirk E: Results and complications of intracranial pressure monitoring in 303 children. Pediatr Neurosurg 23:64-67, 1995

34. Renier D, Lajeunie E, Arnaud E, Marchac D: Management of craniosynostoses. Childs Nerv Syst 16:645-658, 2000

35. Renier D, Sainte-Rose C, Marchac D, Hirsch JF: Intracranial pressure in craniostenosis. J Neurosurg 57:370-377, 1982

36. Seruya M, Oh AK, Boyajian MJ, Posnick JC, Keating RF: Treatment for delayed presentation of sagittal synostosis: challenges pertaining to occult intracranial hypertension. $\mathbf{J}$ Neurosurg Pediatr 8:40-48, 2011

37. Shah MN, Kane AA, Petersen JD, Woo AS, Naidoo SD, Smyth MD: Endoscopically assisted versus open repair of sagittal craniosynostosis: the St. Louis Children's Hospital experience. J Neurosurg Pediatr 8:165-170, 2011

38. Speltz ML, Endriga MC, Mouradian WE: Presurgical and postsurgical mental and psychomotor development of infants with sagittal synostosis. Cleft Palate Craniofac J 34:374379, 1997

39. Starr JR, Kapp-Simon KA, Cloonan YK, Collett BR, Cradock MM, Buono L, et al: Presurgical and postsurgical assessment of the neurodevelopment of infants with singlesuture craniosynostosis: comparison with controls. J Neurosurg 107 (2 Suppl):103-110, 2007

40. Tatum SA, Jones LR, Cho M, Sandhu RS: Differential management of scaphocephaly. Laryngoscope 122:246-253, 2012 (Erratum in Laryngoscope 123:1318, 2013)

41. Taylor JA, Maugans TA: Comparison of spring-mediated cranioplasty to minimally invasive strip craniectomy and barrel staving for early treatment of sagittal craniosynostosis. J Craniofac Surg 22:1225-1229, 2011

42. Thompson DN, Harkness W, Jones B, Gonsalez S, Andar U, Hayward R: Subdural intracranial pressure monitoring in craniosynostosis: its role in surgical management. Childs Nerv Syst 11:269-275, 1995

43. Thompson DN, Malcolm GP, Jones BM, Harkness WJ, Hayward RD: Intracranial pressure in single-suture craniosynostosis. Pediatr Neurosurg 22:235-240, 1995

44. Toma R, Greensmith AL, Meara JG, Da Costa AC, Ellis LA, Willams SK, et al: Quantitative morphometric outcomes following the Melbourne method of total vault remodeling for scaphocephaly. J Craniofac Surg 21:637-643, 2010

45. Tuite GF, Chong WK, Evanson J, Narita A, Taylor D, Harkness WF, et al: The effectiveness of papilledema as an indicator of raised intracranial pressure in children with craniosynostosis. Neurosurgery 38:272-278, 1996

46. Tuite GF, Evanson J, Chong WK, Thompson DN, Harkness WF, Jones BM, et al: The beaten copper cranium: a correlation between intracranial pressure, cranial radiographs, and computed tomographic scans in children with craniosynostosis. Neurosurgery 39:691-699, 1996

47. van Veelen ML, Eelkman Rooda OH, de Jong T, Dammers R, van Adrichem LN, Mathijssen IM: Results of early surgery for sagittal suture synostosis: long-term follow-up and the occurrence of raised intracranial pressure. Childs Nerv Syst 29:997-1005, 2013

48. van Veelen ML, Mathijssen IM: Spring-assisted correction of sagittal suture synostosis. Childs Nerv Syst 28:1347-1351, 2012

49. Vinchon M, Pellerin P, Baroncini M, Wolber A, Dhellemmes 
P: Non-syndromic oxycephaly and brachycephaly: a review. Childs Nerv Syst 28:1439-1446, 2012

50. Wiegand C, Richards P: Measurement of intracranial pressure in children: a critical review of current methods. Dev Med Child Neurol 49:935-941, 2007

51. Wilkie AO, Wall SA: Craniosynostosis: novel insights into pathogenesis and treatment. Curr Opin Neurol 9:146-152, 1996

52. Windh P, Davis C, Sanger C, Sahlin P, Lauritzen C: Springassisted cranioplasty vs pi-plasty for sagittal synostosis-a long term follow-up study. J Craniofac Surg 19:59-64, 2008

\section{Author Contributions}

Conception and design: Thomas, Johnson, Richards, Wall.
Acquisition of data: Thomas, Johnson, Byren, Jayamohan, Magdum, Richards, Wall. Analysis and interpretation of data: Thomas, Richards, Wall. Drafting the article: Thomas, Johnson, Judge, Richards, Wall. Critically revising the article: Thomas, Johnson, Jayamohan, Magdum, Richards, Wall. Reviewed submitted version of manuscript: Thomas, Jayamohan, Magdum, Richards, Wall. Approved the final version of the manuscript on behalf of all authors: Thomas. Statistical analysis: Thomas, Judge. Administrative/technical/material support: Byren, Study supervision: Johnson, Wall.

\section{Correspondence}

Gregory P. L. Thomas, Oxford Craniofacial Unit, Oxford University Hospitals NHS Trust, Headley Way, Oxford OX3 9DU, United Kingdom. email: gplthomas@gmail.com. 